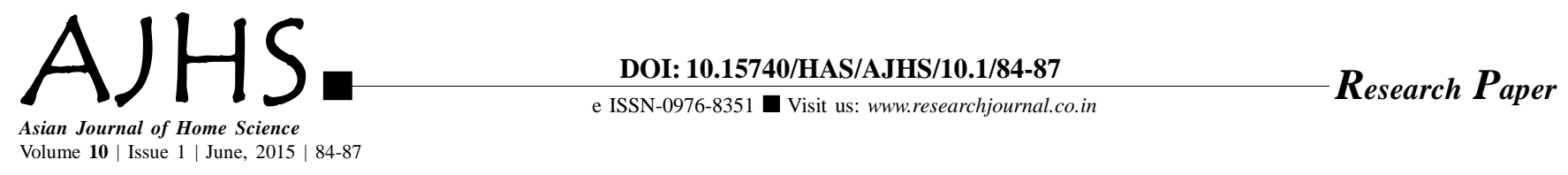

\title{
Designing of dresses for pre-school girls
}

\author{
MINTI GOGOI AND BULBUL BARUAH
}

Received: 13.11.2014; Revised: 28.03.2015; Accepted: 13.04 .2015

See end of the paper for authors' affiliations MINTI GOGOI

Department of Textile and Apparel Design, College of Home Science, Assam Agricultural University, JORHAT (ASSAM) INDIA

Email : mintigogoi@gmail.com
ABSTRACT : The dressing pattern and selection of clothing for every age is an important issue of a family needs. One must be very careful in selection of appropriate dress for children's on the basis of their physiological as well as their psychological needs. All the clothes wear by children should be comfortable, delicate to the skin and it should be appropriate size and designs. Present investigation was carried out on designing of dresses for pre-school girls and the child and mothers preference on 10 ten constructed dresses were recorded. The result shows that colour of dress is the primary factor of their clothing preference.

GEY WORDS: Pre-school, Preference, Designing

- HOW TO CITE THIS PAPER : Gogoi, Minti and Baruah, Bulbul (2015). Designing of dresses for pre-school girls. Asian J. Home Sci., 10 (1) : 84-87. 